\title{
Economic Development in Africa
}

The Cambridge University Overseas Studies Committee sponsored a conference on economic development in Africa at Queens' College from 22 September to s October. Practical aspects of planning for economic development, agrarian progress, and the training of skilled manpower, and the best way in which overseas aid can be given to meet these urgent needs, were discussed. There were three days of plenary sessions at the start of the conference, during which nine papers were presented by experts from the World Bank, the Institute of Race Relations, the Department of Technical Co-operation, the United Nations, the East African Common Service Organization, the American Agency for International Development, the Colonial Office, and the Cambridge University School of Agriculture and Department of Education. Most of the Commonwealth countries in Africa were represented as well as leading international agencies.

\section{Conference on African Studies in Leipzig}

A conference on African Studies in the German Democratic Republic was held at the Africa Institute of the Karl-Marx University of Leipzig on 6 May 1963, this being the tenth anniversary of the renaming of the University. African guests from Tanganyika, Nigeria, and Nyasaland, scientists from Czechoslovakia and various universities and colleges of the German Democratic Republic, as well as representatives of social organizations and public institutions, participated in the conference.

At the plenary session the Director of the Africa Institute, Dr. K. Büttner, spoke about the basis, traditions, and outlook of African studies in the German Democratic Republic. $\mathrm{He}$ emphasized that these consist of research into the history, economy, culture, and state development of African peoples, based upon the theory and methods of Marxism-Leninism. He characterized African studies as a practical science which aims to assist the fight of African peoples.

A number of representatives from various academic institutions, e.g. the Oriental Institute of the Czechoslovak Academy of Sciences, Prague, members of the Africa Institute and of the Institute of Egyptology of the Humboldt University, Berlin, and of the German Academy of Sciences, Berlin, participated in the discussions which took place in the section on African languages. Part of the contributions to this dealt with questions of Hausa grammar, such as the formation of the plural, the structure of relative clauses, and research into the vocabulary of Hausa.

\section{(Communicated by Mr. S. Wintruff)}

\section{'International Information Service'}

THE first number of a quarterly, International Information Service, has recently been published by the Library of International Relations, with the object of providing ' a guide to the wealth of source materials now available on all parts of the world and to offer what it considers to be a selection of the most reliable and significant publications for a balanced and objective interpretation of current developments'. These materials (with certain exceptions) will be made available through the Library's inter-library loan and photo-copy service. The contents of the quarterly are arranged by subjects, with sub-divisions by areas. Atlases, Yearbooks, and Directories are listed at the end and information given as to where the journals listed may be purchased. There is a geographical index. International Information Service may be obtained from the Library of International Relations, 660 North Wabash Avenue, Chicago I I, Ill.; the subscription is $\$ 10.00$ per year, single copies $\$ 3.00$. 